\title{
Phenotypic and genotypic profile of pyrethroid resistance in populations of the mosquito Aedes aegypti from Goiânia, Central West Brazil
}

\author{
Francesca Guaracyaba Garcia Chapadense ${ }^{[1]}$, Everton Kort Kamp Fernandes ${ }^{[1]}$, \\ José Bento Pereira Lima ${ }^{[2],[3],}$ Ademir Jesus Martins ${ }^{[2],[3], ~ L u a n a ~ C a r r a r a ~ S i l v a ~}{ }^{[2],[3],}$ \\ Welington Tristão da Rocha ${ }^{[4]}$, Adelair Helena dos Santos ${ }^{[1]}$ and Pedro Cravo[ ${ }^{[1]}$
}

[1]. Instituto de Patologia Tropical e Saúde Pública, Universidade Federal de Goiás, Goiânia, Goiás, Brazil. [2]. Laboratório de Fisiologia e Controle de Artrópodes Vetores, Instituto Oswaldo Cruz, Fundação Oswaldo Cruz, Rio de Janeiro, Brazil. [3]. Laboratório de Entomologia, Instituto de Biologia do Exército, Rio de Janeiro, Brazil. [4]. Departamento de Vigilância em Saúde Ambiental, Secretaria de Saúde, Goiânia, Goiás, Brazil.

\begin{abstract}
Introduction: The mosquito Aedes aegypti has evolved resistance to pyrethroid insecticides. The present study evaluated Ae. aegypti from Goiânia for the resistant phenotype and for mutations associated with resistance. Methods: Insecticide dose-response bioassays were conducted on mosquitoes descended from field-collected eggs, and polymerase chain reaction (PCR) was used to genotype 90 individuals at sites implicated in pyrethroid resistance. Results: All mosquito populations displayed high levels of resistance to deltamethrin, as well as high frequencies of the 1016Ile ${ }^{k d r}$ and 1534Cyskdr mutations. Conclusions: Aedes aegypti populations in the Goiânia area are highly resistant to deltamethrin, presumably due to high frequencies of $k d r$ (knockdown-resistance) mutations.
\end{abstract}

Keywords: Aedes aegypti. Resistance. Voltage-gated sodium channel.

In tropical areas, Aedes aegypti is the main vector of severe diseases, including some, such as dengue and chikungunya, for which effective vaccines or treatments do not exist. Vector control is therefore critical for public health ${ }^{(1)}$. Worldwide, pyrethroids (PYs) are the most common class of insecticides used to control adult insects ${ }^{(2)}$. However, prolonged use of these insecticides has resulted in the evolution of PY-resistant mosquito populations in many countries, including Brazil ${ }^{(3)}{ }^{(4)}$.

Pyrethroids act by binding to subunits of voltage-gated sodium channels in insects' central nervous systems, keeping these channels in the open state. In Aedes aegypti, substitution mutations in the gene coding for these channels $(A a N a(\mathrm{~V}))$ can alter the conformation of the site where PYs typically bind, leading to resistant mosquitoes ${ }^{(5)}$. In Aedes aegypti, several studies have documented genetic polymorphisms in $\mathrm{AaNa}(\mathrm{V})^{(4)(5)(6)(7)(8)(9)}$, but only two substitutions (Val1016Ile and Phe1534Cys) are clearly related to resistance to $\mathrm{PYs}^{(9)}$.

The State of Goiás, located in Central-West Brazil, is home to approximately 6.5 million people. It is one of the

Corresponding author: Ms. Francesca Guaracyaba Chapadense. Rua 235 s/n, Setor Leste Universitário, 74605-050 Goiânia, Goiás, Brasil.

Phone: 5562 3209-6109; Fax: 5562 3209-6363

e-mail: chapadense.garcia@gmail.com

Received 6 March 2015

Accepted 29 April 2015 states in Brazil most affected by dengue, with 163,808 cases reported in 2013 alone Secretária de Saúde do Estado de Goiás (SES-GO), 2014, unpublished data). More recently, sporadic cases of chikungunya have been reported and it is expected that the disease will soon become epidemic in Goiás.

For over 20 years, the PY deltamethrin has been the main Ae. aegypti adulticide in the State of Goiás. Little is known about tolerance to deltamethrin, or about genetic variation in the $A a N a(\mathrm{~V})$ gene, in populations of $A$ e. aegypti. We evaluated deltamethrin tolerance of Ae. aegypti individuals from three populations in the City of Goiânia, Goiás, and determined the frequency of genetic polymorphisms in residues 1016 and 1534 of the $A a N a(\mathrm{~V})$ gene in these populations. The study was approved by the Committee on the Ethics of Animal Use (ECAU) of the Federal University of Goiás [Universidade Federal de Goiás (UFG)], filed under number 031/13.

Aedes aegypti eggs were collected using ovitraps from three neighborhoods (Vila Finsocial, Sudoeste, and Jardim América) between March and April 2013, according to the protocol of the Brazilian Program for Dengue Control. Egg hatching and species identification followed the procedures of $\mathrm{Lima}^{(10)}$. The larvae were used to establish three laboratory colonies, one from the eggs collected from each of the three neighborhoods. When these larvae reached adulthood, thirty adult males ( $\mathrm{F}_{0}$ generation) were genotyped at positions 1016 and 1534 of the $A a N a(\mathrm{~V})$ locus. For position 1016, conventional polymerase chain reaction (PCR) amplification was used, and amplicon 
sizes were verified in polyacrylamide gels, following previously published protocols ${ }^{(4)}$. For position 1534, allele-specific real time polymerase chain reaction (RT-PCR) was used, as described previously ${ }^{(6)}$.

The remaining $\mathrm{F}_{0}$ adults were allowed to breed, and their offspring $\left(\mathrm{F}_{1}\right.$ generation) were assayed for resistance to deltamethrin. Nine concentrations of insecticide were used: $2.5 \mathrm{mg} / \mathrm{m}^{2}, 5 \mathrm{mg} / \mathrm{m}^{2}, 15 \mathrm{mg} / \mathrm{m}^{2}, 30 \mathrm{mg} / \mathrm{m}^{2}, 40 \mathrm{mg} / \mathrm{m}^{2}, 50 \mathrm{mg} / \mathrm{m}^{2}$, $75 \mathrm{mg} / \mathrm{m}^{2}, 100 \mathrm{mg} / \mathrm{m}^{2}$, and $125 \mathrm{mg} / \mathrm{m}^{2}$. From each of the three colonies, $20 \mathrm{~F}_{1}$ females 3-5 days post-eclosion were selected for each of these treatments, and placed in cylindrical plastic tubes containing paper impregnated in permethrin at the indicated concentration. In this sense, around 60 females were exposed to each concentration and to the untreated control, totalizing around 600 females/population. Tolerance to deltamethrin was estimated by comparing mortality of the Goiânia mosquitoes to those of the insecticide-susceptible Rockefeller strain, as recommended by the World Health Organization (WHO) ${ }^{(11)}$, insecticidal the same concentrations and the same number of female population were used to Rockfeller Probit analysis was performed with Polo-PC ${ }^{(12)}$, with $\alpha=0.05$, to obtain lethal concentracion $\mathrm{LC}_{50}$ and $\mathrm{LC}_{95}$ values for the three Goiânia colonies and the Rockefeller strain. The resistance ratio (RR) for each of the Goiânia populations was calculated as the ratio between the $\mathrm{LC}_{50}$ or $\mathrm{LC}_{95}$ of the Goiânia colonies and that of the Rockefeller strain.

A total of 7,400 eggs were collected. Of the 180 traps, $121(67 \%)$ had fertile eggs. From the total number of eggs in each trap, an Ovitrap Positivity Index (OPI) was calculated. The OPIs of the Vila Finsocial, Sudoeste and Jardim América were $78.3 \%, 70 \%$, and $53 \%$, respectively. Successful hatching rates ranged from $64 \%$ to $75.5 \%$. All populations showed the expected sex ratio of $1: 1$.

All of the Goiânia populations of Ae. aegypti showed high levels of resistance to deltamethrin (Figure 1). This is similar to trends seen in other regions of Brazil ${ }^{(3)(4)(9)}$. As suggested by Chandrer ${ }^{(13)}$, this is likely to be a result of the selection pressure imposed by the application of large amounts of the same group of insecticides over a long period of time. $k d r$ (knockdown resistant) substitutions at both site 1016 and 1534 were seen at high frequencies in the three districts surveyed. Frequencies for the $1016 \mathrm{Ile} \mathrm{e}^{k d r}$ substitution ranged from 0.47 to 0.72 , with homozygotes for this substitution ranging from 0.23 to 0.60 . The frequency of the $1534 \mathrm{Cys}^{k d r}$ substitution was nearly 1.0 in all of the Goiânia populations; only one individual was heterozygous for this substitution (Table 1). A significant fraction of mosquitoes carried two copies of both substitutions (Table 2), which may confer higher levels of resistance to $\mathrm{PYs}^{(9)}$.

In conclusion, having characterized three Ae. aegypti populations from Goiânia in Central-West Brazil for their tolerance to deltamethrin and for mutations in the $A a N a(\mathrm{~V})$ gene that are known to be implicated in insecticide resistance, we found that all populations exhibit high resistance to deltamethrin, consistent with the high frequency of mutations that we observed in the $A a N a(\mathrm{~V})$ gene. Our data support the position that pyrethroids are no longer effective for suppressing Ae. aegypti in Goiás. Due to the competence and efficiency of this vector in the transmission of diseases such as yellow fever, dengue, and chikungunya, we conclude that there is an urgent demand for alternative and/or complementary methods of vector control.

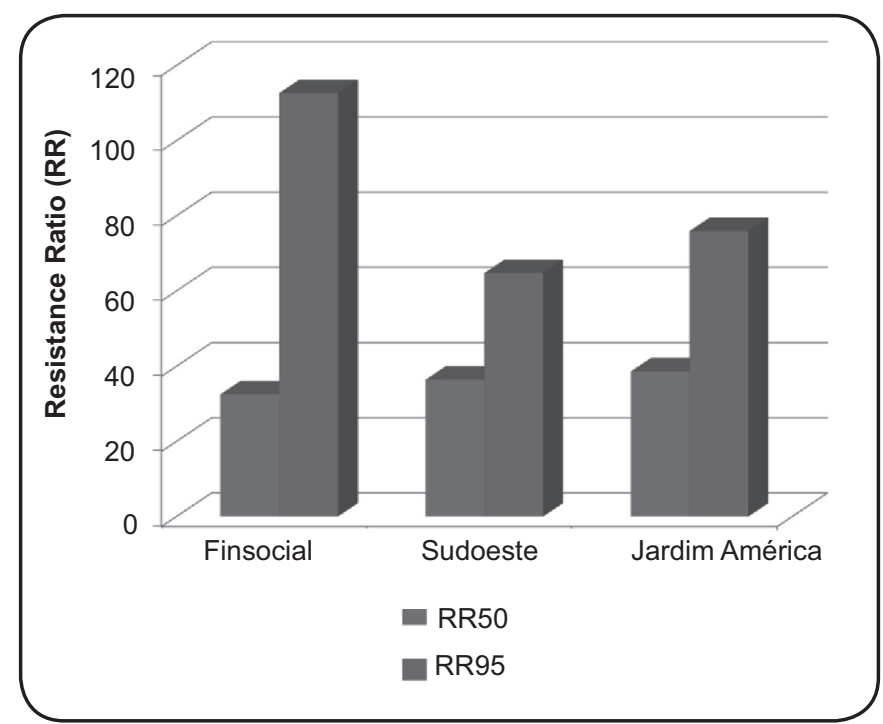

FIGURE 1 - Deltamethrin resistance ratios for three Aedes aegypti populations from the City of Goiânia, Central-West Brazil. Resistance ratios for each population were calculated from the ratio between the $\mathrm{LC}_{50}$ or $\mathrm{LC}_{95}$ of the field sample and that of the susceptible Rockefeller strain. Bars represent the average RRs resulting from three independent experiments. RR: resistance ratios; $\mathbf{L C}$ : lethal concentration.

TABLE 1 - Genotypic and allelic frequencies for each of the 1016 and 1534 AaNa(V) sites of Aedes aegypti populations from Goiânia, Central-West, Brazil.

\begin{tabular}{|c|c|c|c|c|c|c|c|c|c|c|c|c|}
\hline \multirow[b]{3}{*}{ District } & \multicolumn{6}{|c|}{1016} & \multicolumn{6}{|c|}{1534} \\
\hline & \multicolumn{4}{|c|}{ genotypes } & \multicolumn{2}{|c|}{ alleles } & \multicolumn{4}{|c|}{ genotypes } & \multicolumn{2}{|c|}{ alleles } \\
\hline & $\overline{\mathbf{N}}$ & Val/Val & Val/Ile & $\overline{\text { Ile/Ile }}$ & Val & $\overline{\text { Ile }(k d r)}$ & $\mathbf{N}$ & Phe/Phe & Phe/Cys & $\overline{\text { Cys/Cys }}$ & Phe & Cys $(k d r)$ \\
\hline Sudoeste & 30 & 0.300 & 0.470 & 0.230 & 0.530 & 0.470 & 28 & 0 & 0 & 1 & 0 & 1 \\
\hline Jardim América & 30 & 0.160 & 0.230 & 0.600 & 0.280 & 0.720 & 26 & 0 & 0 & 1 & 0 & 1 \\
\hline
\end{tabular}

N: total number of samples. 
TABLE 2 - Number and frequency of genotypes of Aedes aegypti populations from Goiânia, Central-West Brazil. Possible alleles are S (1016 Val $\left.{ }^{+}+1534 \mathrm{Phe}^{+}\right)$, R1 (1016 $\left.\mathrm{Val}^{+}+1534 \mathrm{Cys}^{k d r}\right)$, and R2 (1016 Ile $\left.{ }^{k d r}+1534 \mathrm{Cys}^{k d r}\right)$, where + denotes wild-type and $k d r$ denotes substitutions conferring knockdown resistance.

\begin{tabular}{|c|c|c|c|c|c|c|c|c|c|c|c|c|c|c|c|c|}
\hline District & \multicolumn{2}{|c|}{ SS } & \multicolumn{2}{|c|}{ SR1 } & \multicolumn{2}{|c|}{ R1R1 } & \multicolumn{2}{|c|}{ SR2 } & \multicolumn{2}{|c|}{ R1R2 } & \multicolumn{2}{|c|}{ R2R2 } & \multicolumn{2}{|c|}{ Total (n) } & $\begin{array}{c}\text { HWE } \\
* \chi 2\end{array}$ & $\mathbf{p}$ \\
\hline Sudoeste & 0 & 0 & 0 & 0 & 4 & 0.154 & 0 & 0 & 7 & 0.269 & 15 & 0.577 & 26 & 1 & 3.8 & 0.2883 \\
\hline Jardim América & 0 & 0 & 1 & 0.036 & 10 & 0.357 & 0 & 0 & 6 & 0.214 & 11 & 0.393 & 28 & 1 & 9.1 & 0.0275 \\
\hline Finsocial & 0 & 0 & 0 & 0 & 9 & 0.321 & 0 & 0 & 12 & 0.429 & 7 & 0.250 & 28 & 1 & 0.6 & 0.9016 \\
\hline
\end{tabular}

SS: Wild (Val/Val +Phe/Phe); SR1: wild + heterozygous (Val/Val + Phe/Cys); R1R1: wild + Mutant (Val/Val + Cys/Cys); SR2: heterozygous + heterozygous (Val/Ile + Phe/Cys); R1R2: heterozygous + Mutant (Val/Ile + Cys/Cys); R2R2: mutant + mutant (Ile/lle + Cys/Cys); HWE: Hardy-Weinberg Equilibrium; $\mathrm{n}$ : number; fr: frequency. * $\chi 2$ : test value and $\mathrm{p}$ assuming 3 degrees of freedom.

\section{CONFLICT OF INTEREST}

The authors declare that there is no conflict of interest.

\section{FINANCIAL SUPPORT}

Coordenação de Aperfeiçoamento de Pessoal de Nivel Superior (CAPES), M. Sc. Grant N. 1088561. Pedro Cravo is a productivity fellow of the National Council of Technological and Scientific Development [Conselho Nacional de Desenvolvimento Cientifico e Tecnológico (CNPq)] of Brazil.

\section{REFERENCES}

1. Gubler DJ. Dengue and dengue hemorrhagic fever. Clin Microbiol Rev 1998; 11:480-496

2. Lima EP, Oliveira Filho AM, Lima JWO, Ramos Junior AN, Cavalcanti LPG, Pontes RJS. Resistência do Aedes aegypti ao Temefós em Municípios do Estado do Ceará. Rev Soc Bras Med Trop 2006; 39: 259-263.

3. Da-Cunha MP, Lima JBP, Brogdon WG, Moya GE, Valle D. Monitoring of resistance to the pyrethroid cypermethrin in Brazilian Aedes aegypti (Diptera: Culicidae) populations collected between 2001 and 2003. Mem Inst Oswaldo Cruz 2005; 100:441-444.

4. Martins AJ, Lima JB, Peixoto AA, Valle D. Frequency of Val1016Ile mutation in the voltage-gated sodium channel gene of Aedes aegypti Brazilian populations. Trop Med Int Health 2009; 14:1351-1355.

5. Sanderlund DM. Pyrethroids, knockdown resistance and sodium channels. Pest Manag Sci 2008; 64:610-616.
6. Saavedra-Rodriguez K, Urdaneta-Marquez L, Rajatileka S, Moulton M, Flores AE, Fernandez-Salas I, et. al. A mutation in the voltage-gated sodium channel gene associated with pyrethroid resistance in Latin American Aedes aegypti. Insect Biochem Mol Biol 2007; 16:785-798.

7. Cheng C, Wen-kai S, Tzu-ting WB, Ying-hsi L, Err-lieh H, Shu-mei D. A novel amino acid substitution in a voltage-gated sodium channel is associated with knockdown resistance to permethrin in Aedes aegypti. Rev Insect Biochem Mol Biol 2009; 39:272-278.

8. Yanola J, Somboon P, Walton C, Woottichai N, La-aied P. A novel F1552/C1552 point mutation in the Aedes aegypti voltage-gated sodium channel gene associated with permethrin resistance. Pestic Biochem Physiol 2010; 96:127-131.

9. Linss JGB, Brito LP, Garcia GA, Araki AS, Bruno RV, Lima JBP, et. al. Distribution and dissemination of the Val1016Ile and Phe1534Cys $k d r$ mutations in Aedes aegypti Brazilian natural populations. Parasit Vectors 2014; 7:1-11.

10. Lima WP, Chiaravalloti Neto F, Macoris MLG, Zuccari DAPC. Estabelecimento de metodologia para alimentação de Aedes aegypti (Diptera-Culicidae) em camundongos swiss e avaliação da toxicidade e do efeito residual do óleo essencial de Tagetes minuta L (Asteraceae) em populações de Aedes aegypti. Rev Soc Bras Med Trop 2009; 42:638-641.

11. World Health Organization (WHO). Test procedures for insecticide resistance monitoring in malaria vectors, bio efficacy and persistence of insecticides on treated surfaces. WHO/CDS/CPC/ MAL/98.12. Geneva: WHO; 1998.

12. Raymond M. Présentation d'un programmed'analyse logprobit pour micro-ordinateur. Cah. O.R.S.T.O.M. Ser Entomol Med Parasitol 1985; 22:117-121.

13. Chandrer F, Darrier F, Manga L, Akogbeto M, Faye O, Mouchet J, et. al. Status de pyrethroid resistance in Anopheles gambiae sensulato. Bull World Health Organ 1999; 77:230-234. 